\title{
Processo de Municipalização: uma avaliação do nível de informação dos profissionais de Saúde das Unidades Básicas da região oeste do município de Londrina - Paraná
}

\author{
Maria Lúcia da Silva Lopes ${ }_{2}^{1}$ \\ Vânia de Oliveira Melo ${ }^{2}$ \\ Rosieli Alves Chiaratto ${ }^{3}$ \\ Luiz Cordoni Júnior ${ }^{4}$ \\ Cristiane de Andrade Janene Gonini ${ }^{5}$
}

\section{Introdução}

A Constituição Federal de 1988 (Brasil, 1988) trouxe para a área da saúde possibilidades de profundas modificações, especialmente no que se refere à "... viabilidade de superação do fetiche do planejamento central e implantação concreta da descentralização político-administrativa" (Mendes, 1993, p.310).

Como conseqüência, abriram-se ou foram ampliadas as vias da municipalização dos serviços de saúde, hoje em processo, em muitas regiões do país.

Em Londrina, a municipalização iniciou-se na segunda metade da década de setenta (Almeida, 1979) de modo autônomo, ganhando impulso nas décadas de oitenta $e$ noventa com o projeto de Extensão de Cobertura da Secretaria de Saúde do Paraná, as Ações Integradas de Saúde, o Sistema Unificado e Descentralizado de Saúde e o Sistema único de Saúde (SUS). Esse processo levou à descentralização dos serviços, com a multiplicação de Unidades Básicas de Saúde (UBS) na periferia urbana e região rural, chegando a 44 unidades em 1990. A partir dessa época houve questionamentos aos paradigmas que orientavam o modelo assistencial vigente, desembocando na adoção de um novo paradigma, o de vigilância à saúde que encontra, na distritalização, sua concretude.

Objetivando a construção de um novo modelo que enfatizasse a intervenção sobre a realidade local por meio de mudanças das práticas sanitárias, iniciaram-se em Londrina discussões e intervenções que culminaram na realização das oficinas de territorialização nas Unidades Básicas de Saúde, as estimativas rápidas participativas $e$ as oficinas de planejamento, coordenadas por um grupo de profissionais da Autarquia Municipal de Saúde. Simultaneamente, ocorreu, em 1994, o treinamento de gerentes de Unidades Básicas de Saúde com o apoio dos docentes do Departamento Materno Infantil e Saúde Comunitária da Universidade Estadual de

\footnotetext{
${ }^{1}$ Enfermeira, Docente do Centro de Estudos Superiores de Londrina, CESULON.

${ }^{2}$ Enfermeira do Instituto de Saúde do Paraná, CESULON.

${ }^{3}$ Cirurgiã-Dentista da Prefeitura de Cambé, Docente da Universidade Norte do Paraná, UNOPAR.

${ }^{4}$ Médico Sanitarista, Docente da Universidade Estadual de Londrina, UEL..

${ }^{5}$ Cirurgiã-Dentista da Autarquia do Serviço Municipal de Saúde de Londrina, Docente da UNOPAR.
} 
Londrina, o Curso de Gerente de Unidades Básicas de Saúde - GERUS, em nível de especialização, destinado a profissionais de nível superior vinculados às UBS.

Por meio dessas estratégias pretendeu-se aproximar os profissionais de saúde das necessidades da população nos seus territórios, bem como interá-los da política de saúde vigente, expressa no SUS.

Esse processo trouxe grandes desafios $e$ gerou importantes mudanças nos serviços de saúde de Londrina; suscitou, porém, a seguinte preocupação: Será que os recursos humanos acompanharam e captaram todo esse processo?

... toda esta municipalização tem dimensões político-ideológicas e pedagógicas objetivando movimentar organicamente os atores sociais do processo de distritalização. A concepção desse processo tem por detrás de si, uma singela constatação: a de que não haverá reforma sanitária se não houver mudança de cada uma das pessoas comuns e correntes que trabalham nos serviços de saúde (Mendes, 1993, p.310).

Com o objetivo de avaliar o nível de informação dos profissionais de saúde das UBS da região Oeste do Município de Londrina que participaram das oficinas de territorialização, sobre tópicos relacionados ao processo de municipalização, analisamos o conhecimento auto-atribuído pelos profissionais de saúde a respeito de territorialização, conferências de saúde, conselhos de saúde e municipalização $e$ aferimos conceitos básicos relacionados ao processo de municipalização por meio de questões objetivas.

\section{Metodologia}

Escolhemos a região Oeste de Londrina, composta de sete UBS, pelo fato de os profissionais das Unidades que a compõem "terem sido muito participativos nas oficinas de territorialização realizadas em Londrina durante o ano de 1993" (Zucolli, 1998) ${ }^{6}$.

Foram entrevistados 139 profissionais de saúde, o que correspondeu a $84,24 \%$ da totalidade de recursos humanos que trabalham na região. Os demais $15,76 \%$, não foram localizados nas UBS por motivos de licença médica, licença maternidade, férias, congressos e conclusão de contratos por tempo determinado.

$\mathrm{O}$ alvo deste trabalho foram os profissionais entrevistados que participaram da oficina de territorialização (totalizando noventa), sendo 17 de nível profissional superior (enfermeiros, dentistas e médicos), 54 de nível profissional médio (auxiliares de enfermagem $e$ técnicos em higiene dental) $e$ 19 de nível profissional elementar (auxiliares de odontologia).

Os procedimentos de coleta de dados envolveram a aplicação de questionários com perguntas abertas e fechadas. Este instrumento incluiu dados de identificação, uma auto-avaliação ${ }^{7}$ dos profissionais em relação aos níveis de conhecimento a respeito de tópicos inerentes à questão da municipalização - Territórios nos Serviços de Saúde, Conferências de Saúde, Conselhos de Saúde, Processo de Municipalização -,e perguntas objetivas $^{8}$ sobre o tema, relacionando-se ao significado da sigla SUS, princípios do SUS, modalidade de gestão em que Londrina se encontrava no processo de municipalização $e$ atividades assumidas pela cidade nessa gestão.

6 ZUCOLLI, M. Comunicação pessoal.

7 Com atribuição de valores variando de 0 a 5 para cada tópico.

8 Questões de múltipla escolha elaboradas a partir de respostas obtidas por questionário piloto. 
Resultados

Com relação ao conhecimento auto-atribuído sobre Territórios, Conferências de Saúde, Conselhos de Saúde e Municipalização, utilizou-se a média dos resultados das quatro questões, observando-se que, nos níveis profissionais elementar e médio, os percentuais mais elevados concentraram-se nos escores dois (conhece pouco e tem dúvidas) e três (conhece o assunto, mas não é capaz de discutir), com índices de $26,32 \%$ e $28,95 \%$ no nível profissional elementar e de $27,78 \%$ e $35,19 \%$, no profissional médio. Em relação aos profissionais de nível superior, o escore quatro (conhece e é capaz de discutir o assunto) foi o mais assinalado, com $39,71 \%$. É importante ressaltar que o escore zero (ausência de conhecimento) apareceu assinalado nos três níveis profissionais, contudo, no elementar, a proporção de indivíduos que revelaram não ter conhecimento algum sobre os quatro tópicos (valor zero), ou que somente ouviram falar a respeito (valor um), correspondeu a aproximadamente $32 \%$ dos entrevistados. Parece-nos que esta constatação relaciona-se ao fato de que esta categoria representa os auxiliares de odontologia, uma classe que, pelas características do seu trabalho, restrito a uma sala fechada $e$ às vezes isolada da Unidade de Saúde, não esteja totalmente integrada à equipe de saúde e, menos ainda, a todo o processo de mudança. Somando-se a isto, tem-se a dificuldade inerente ao grau de escolaridade.

A avaliação global dos resultados parece demonstrar que os recursos humanos atribuíram-se um nível de informação razoável, mas o nível profissional superior apresentou os escores mais altos, com quase dois terços das respostas distribuídas nos valores três (conhece o assunto, mas não é capaz de discuti-lo) e quatro (conhece o assunto e é capaz de discuti-lo).

Um percentual muito pequeno de indivíduos relatou ter pleno conhecimento a respeito dos assuntos abordados (valor cinco). No nível profissional elementar foi encontrada uma média de apenas 1,31\%; no profissional médio; $3,70 \%$; e no profissional superior, $2,94 \%$.

No que se refere às questões abertas dos questionários, que incluíam significado da sigla SUS, princípios do SUS, modalidade de gestão em que Londrina se encontrava no processo de municipalização $e$ atividades assumidas pelo município nessa gestão, observamos que, em relação a sigla SUS, não existiu diferença significativa entre as respostas corretas e incorretas de acordo com o nível profissional, já que a maioria sabia seu significado. Em relação aos princípios do SUS, observamos que, nos níveis elementar e médio, o percentual de respostas incorretas foi bastante elevada $(68,42 \%$, $61,11 \%$, respectivamente); em relação aos profissionais de nível superior, essa relação se inverte, obtendo-se 70,59\% de respostas corretas. Quanto à Modalidade de Gestão em que se encontra Londrina, observamos que, no nível elementar, o maior percentual são de respostas incorretas (57,90\%), enquanto nos níveis médio e superior, foi de respostas corretas (70,37\% e 76,47\%).

Sobre as atividades assumidas pelo município de Londrina, os resultados mostraram que, nos níveis elementar $e$ médio, as respostas incorretas sobressaem-se $(57,9 \%$ e $61,11 \%)$ e que no nível superior as respostas incorretas apresentam $41,18 \%$ e as corretas $58,82 \%$.

\section{Discussão}

$\mathrm{Na}$ avaliação dos conceitos-chave, o maior percentual de acerto foi encontrado entre profissionais de nível superior, com aproximadamente $75 \%$ das respostas corretas, caindo para $69 \%$ no nível médio e pouco mais de $50 \%$ no nível elementar. Ressalta-se que estes valores correspondem a uma média realizada a partir das respostas obtidas em quatro perguntas.

Partindo-se do princípio que os recursos humanos aferidos passaram por oficinas de territorialização (realizadas apenas uma vez em cada U.B.S.), com discussões sobre o novo 
modelo assistencial, os resultados sugerem a necessidade de se dar continuidade ao processo, para que a internalização dos conceitos seja feita a partir de sucessivas aproximações.

Embora a pesquisa indique haver certo grau de informação, há, por outro lado, falhas que podem comprometer o enfrentamento dos problemas apontados, tais como: falta de conhecimento sobre o processo de municipalização, não continuidade das oficinas de territorialização, pouca apropriação do território pelos profissionais, entre outras.

Como exemplo de caminhos possíveis para a solução destes problemas, pode-se citar o que foi deliberado na $4^{a}$ Conferência Municipal de Saúde de Londrina, realizada em setembro de 1995, sobre capacitação e treinamento de recursos humanos: a) implantar projeto específico de treinamento $e$ capacitação de forma permanente $e$ continuada (grifo dos autores) para profissionais de saúde da Autarquia do Serviço Municipal de Saúde e de outros serviços que atuem no Sus; b) promover a integração das diversas instituições formadoras de recursos humanos com as que executam as ações de saúde; c) definir uma política de recursos humanos ... respeitando as diretrizes constitucionais.

Além disso, fazem-se necessárias

... profundas mudanças no marco conceitual da educação superior e técnica, com ênfase em áreas de conhecimento e de práticas que hoje são subalternas nos currículos, à exceção dos cursos específicos de Saúde Pública ou Coletiva. Como parte das estratégias de mudança, poderia estar a transferência da capacitação técnica e gerencial para as Secretarias Estaduais de Saúde e Secretarias Municipais de Saúde, especialmente no que se refere à educação continuada dos profissionais e trabalhadores do Sus (Teixeira, 1993, p.20).
Sabemos que não há transformação possível sem a transformação da consciência do pessoal de saúde.

Não se trata, entretanto, da defesa de um fhumanismo ingênuo ... trata-se apenas de reconhecer o trabalho alienado como questão crucial e considerar certas dimensões relevantes da vida do trabalhador de saúde que contribuam para sua valorização, gratificação $e$ realização enquanto ser humano e não apenas como força de trabalho (Paim, 1994, p.80).

Referências bibliográficas

ALMEIDA, M. J. A organização de serviços de saúde a nível local: registros de uma experiência em processo. Rio de Janeiro, 1979. 125p. Dissertação (Mestrado). Instituto de Medicina Social, Universidade do Estado do Rio de Janeiro.

BRASIL. Nova Constituição Brasileira. Brasil: Sistema Jornal do Brasil, Gráfica J. B., 1988.

MENDES, E. V. Distrito sanitário: o processo social de mudança das práticas sanitárias do Sistema Único de Saúde. São Paulo-Rio de Janeiro: Hucitec-Abrasco, 1993.

PAIM, J. S. Recursos humanos em saúde no Brasil: problemas crônicos e desafios agudos. São Paulo: Faculdade de Saúde Pública/USP, 1994.

TEIXEIRA, C.F. Formação de recursos humanos para o SUS: desafios na perspectiva da mudança do modelo de gestão e atenção à saúde. Saúde em Debate, n. 41, p.20-3, 1993.

PALAVRAS-CHAVE: municipalidades; avaliação; prática profissional; área de serviço de saúde.

KEY WORDS: municipal government; evaluation; professional practice; catchment area (health). 